\title{
PARAMETRIC ANALYSIS ON BOIL-OFF GAS RATE INSIDE LIQUEFIED NATURAL GAS STORAGE TANK
}

\author{
Mohamad Shukri Zakaria ${ }^{1}$, Kahar Osman $^{2}$, Ahmad Anas Yusof ${ }^{1}$, Mohamad \\ Hafidzal Mohd Hanafi ${ }^{1}$, Mohd Noor Asril Saadun ${ }^{1}$ and Muhammad Zaidan \\ Abdul Manaf ${ }^{1}$ \\ ${ }^{\mathbf{1}}$ Faculty of Mechanical Engineering, Universiti Teknikal Malaysia Melaka \\ Hang Tuah Jaya, 76100 Durian Tunggal, Melaka, Malaysia \\ Email: mohamad.shukri@utem.edu.my \\ ${ }^{2}$ Faculty of Mechanical Engineering, Universiti Teknologi Malaysia, \\ 81310 Skudai, Johor, Malaysia \\ Email: kahar@fkm.utm.my
}

\begin{abstract}
Research into the environmental effect of greenhouse emissions is now intense. One of the sources contributing to the effect is boil-off gas (BOG) flaring into the atmosphere. BOG formation is caused by heat leakage from the liquefied natural gas (LNG) storage tank. Heat leakages are determined by the effectiveness of heat thermal transmittance of the structural tank and ambient condition. The objective of this present study is therefore to determine the relationship between heat thermal transmittance and ambient condition, and the boil-off rate for a specific $40,447 \mathrm{~m}^{3} \mathrm{LNG}$ tank size corresponding to a $160,000 \mathrm{~m}^{3}$ LNG ship size. General estimations of the amounts of BOG generated are useful in determining the amount of BOG that will need to flare in order to control the greenhouse effect and the amount of pollution entering the environment. This study analyzes both the steady and unsteady behavior of heat transfer mechanisms using ANSYS Fluent software. Results show that dynamic transient simulation only takes effect on the first five days of a voyage. There is then a linear relationship between the investigated parameters of the boil-off rate of LNG. These linear relations are of the utmost use for LNG tank manufacturer and researchers requiring a preliminary view in order to determine LNG tank specification. The result obtained is also validated by studies by previous researcher.
\end{abstract}

Keywords: Liquefied natural gas; boil-off gas; heat transfer; greenhouse emission; pollution.

\section{INTRODUCTION}

Current concerns about greenhouse gas (GHG) emissions has popularized Natural Gas as an energy source compared to crude oil or coal. There are two main methods of transporting the energy sources from offshore fields to terminals: via pipeline or via ship. For long distance transportation, the liquid form of natural gas, liquefied natural gas (LNG), is favorable for transportation by ship due to the high volume ratio (600 times) of gas to the liquid phase occurring at the cryogenic boiling temperature of LNG $\left(-163^{\circ} \mathrm{C}\right)$. The main challenge is to make sure LNG is at least at saturated temperature in order to maintain its liquid state. The formation of vapor inside the closed storage tank will build up pressure, causing safety issues. Conventional and simple methods of handling excess BOG are therefore venting and torching to the atmosphere. These 
methods involve several issues such as pollution, energy waste and economic waste. In this paper, heat transfer analysis was used to estimate the amount of vapor produced during storage under several critical parameters. The formation of BOG inside an LNG tank is governed by several critical parameters, addressed by (Hasan, Zheng, \& Karimi, 2009): sea condition, LNG grade, ambient temperature, heat thermal transmittance U, tank pressure, and operating mode.

Several researchers (Adom, Islam, \& Ji, 2010; Chen, Wegrzyn, \& Prasad, 2004; Dimopoulos \& Frangopoulos, 2008; Gharehghani, Hosseini, \& Yusaf, 2013; Hasan et al., 2009; Ming-shun, Bo-yang, \& Yun-qiu, 2009; Querol, GonzalezRegueral, García-Torrent, \& García-Martínez, 2010; Shin, Shin, Choi, \& Yoon, 2008; Yusaf, Baker, Hamawand, \& Noor, 2013; Zellouf \& Portannier, 2011) have studied LNG evaporation rate models and the standard BOR was reported to be in the range of $0.1 \% \mathrm{~kg} / \mathrm{kg}$ per day to $0.15 \% \mathrm{~kg} / \mathrm{kg}$ per day. However the applications of the model are strongly limited to specific parameters and the consideration of a large number of variables and assumptions make the estimation unrealistic. To the writer's knowledge, no rate of BOG has been calculated for large scale LNG tanks in the literature, account for the effect of the critical parameter in details even for rough estimation of boil off rate. In this paper, realistic parameters and assumptions are used so that industries, tank manufacturers, engineers or researchers are have a main reference in order to design new and improved LNG tanks based on required BOR specifications.

\section{COMPUTATIONAL GEOMETRY AND GRID}

The geometry of the LNG tank used in the present study is shown in the Figure 1, in two dimensions for illustration purposes, however, a three dimensional model was used in the simulation. The full scale amin dimensions are $37.9 \mathrm{~m}$ breadth (b) tank, $43.72 \mathrm{~m}$ length $(l)$ (in z-direction), and 26.75 height $(h)$. The lower and upper chamfer angles are both $135^{\circ}$. The lower chamfer height $\left(h_{L}\right)$ is $3.77 \mathrm{~m}$ while the upper chamfer height $\left(h_{u}\right)$ is $8.63 \mathrm{~m}$. This geometry is based on a tank compartment of typical tank ship size $160000 \mathrm{~m}^{3}$, with about $40447 \mathrm{~m}^{3}$ tank size. The scope of interest in the analysis involves only the structural and insulation from the outer shell of the tank up to the inner membrane of the tank exposed to the cargo. In a typical LNG membrane type tank, the structural thickness is approximately $3 \mathrm{~m}$ and insulation thickness approximately $0.53 \mathrm{~m}$ (Romero \& Mosquera, 2005). In this paper, both sections of the structural part and the insulation part are assumed to have a total thickness of $0.53 \mathrm{~m}$. The assumption is encounter with the corrected thermal conductivity taken as $0.0605 \mathrm{~W} / \mathrm{h} . \mathrm{m} . \mathrm{K}$ for the main insulation material made of polyurethane foam. Using the well-known Equation (1), one is able to compute the heat thermal transmittance $\mathrm{U}$ for $0.411 \mathrm{~kJ} / \mathrm{h} \cdot \mathrm{m}^{2} . \mathrm{K}$.

$$
\frac{1}{U}=\frac{1}{h_{1}}+\frac{x}{k}+\frac{1}{h_{2}}
$$

where $h_{1}$ and $h_{2}$ are free stream heat transfer coefficients for the ambient side and the cargo side is taken as $30 \mathrm{w} / \mathrm{m}^{2} \mathrm{~K}$ and $3000 \mathrm{w} / \mathrm{m}^{2} \mathrm{~K}$ respectively.

The corresponding volume covers the area from the outer shell to the inner membrane exposed to the cargo, which was tested for grid independence when it was found that the meshes with 306,067 tetrahedral element types give the same result if the number of elements is increased. 


\section{BOUNDARY CONDITIONS AND ASSUMPTION}

In a typical LNG trading vessel, it is assumed that the typical draught, which is line between air and water is around 10 meters, which can been seen from maximum draught admitted for random LNG terminal around the world as reported by (Romero \& Mosquera, 2005). This draught is important to separate the temperature above and below the water level which is different in different cases depending on voyage location. Different combinations of seawater and air temperature are chosen based on United States Coast Guard (USCG) requirements. This condition may generally be used for worldwide services, as per "The International Code for the Construction and Equipment of Ships Carrying Liquefied Gases in Bulk" [IGC code], and will be used as part of the analysis in this paper. A lesser ambient temperature will favor less boil off, however it will affect the condition of the hull material where it is exposed to very cold temperatures. The temperature inside the cofferdam is taken as constant at $5^{\circ} \mathrm{C}$, controlled by a heating element in order to satisfy minimum allowable design temperature. In this paper the structural behavior has not been considered because it does not affect the BOR and it will represent in terms of overall heat transfer coefficient.

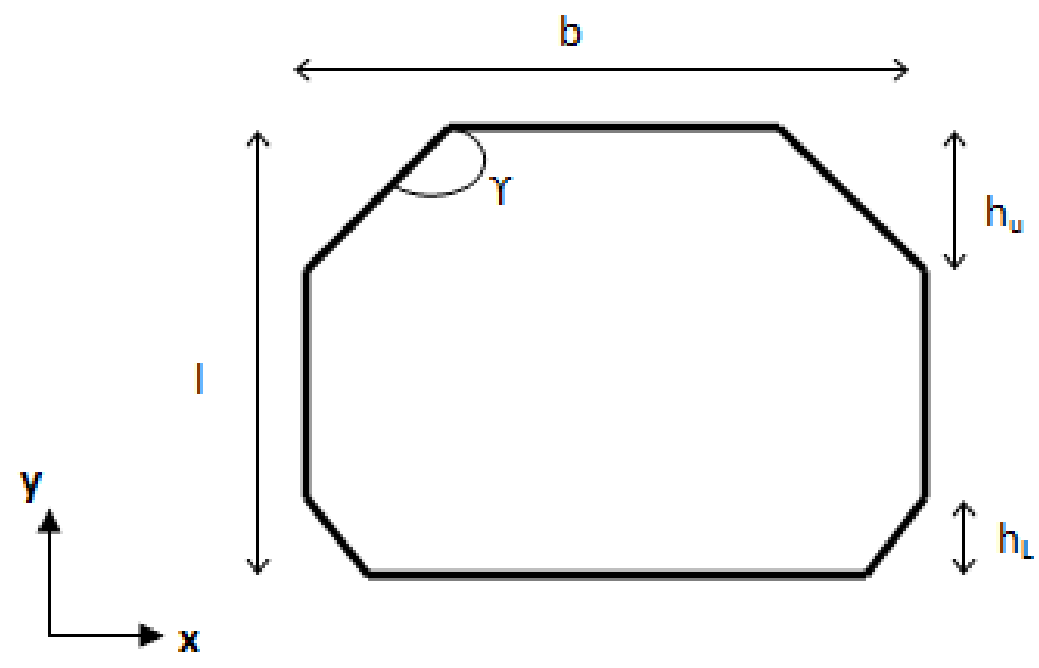

Figure 1. Membrane type LNG tank geometry and cross section showing upper height $\left(h_{u}\right)$, lower height $\left(h_{1}\right)$, breadth $(b)$, length $(l)$, and chamfer angle $(\gamma)$.

The main factor influencing the amount of BOG generated is the overall heat transfer coefficient, $U$ which is affected by the multi-layered wall between the outer hull of the ship and the inner surface of insulation that is exposed to the cargo. It consists of a complex structure and arrangement of material such as evacuate perlite, INVAR membrane, boxes, resin composition, area of strut junction, different sizes of aggregate, inner and outer steel grade and so on. Details of multilayer insulation have been studied by (Chen et al., 2004) especially the insulation thickness and area of the strut junction connecting the outer and inner hull of the ship. The typical value $U$ is around 0.411 $\mathrm{kJ} / \mathrm{h} . \mathrm{m} 2 . \mathrm{K}$ for polyethylene type insulation and with area of support junction is $0.0001 \%$ is observed by (Hasan et al., 2009) and (Chen et al., 2004) will be used as part of analysis. In addition, several values of $U$ are used in a case study in this paper to determine the corresponding amount of BOG produced. It is worth assuming that the LNG grade consists of $100 \%$ methane since a typical LNG grade consists of around 
90\% of methane. Furthermore, a higher methane component in LNG will favor the generation of more BOG, as investigated by Ebenezer (2010) and Hasan, et al. (2009). The worst case of the LNG grade consisting of $100 \%$ methane was thus considered for the optimization study. In standard practice, even the maximum allowable working pressure for an LNG structure tanker is around 14 bars, and the operating pressure for LNG transportation is maintained slightly above 1 bar to make sure safety is guaranteed. So that, in this paper one used constant operation pressure at 1 bar which was affected the key value of latent heat vaporization as observed by Querol et al. (2010).

\section{BOR ESTIMATION}

BOR is defined in this paper as the percentage of Natural Gas (NG) created from the LNG phase due to heat leakage through a storage vessel while maintaining its saturated temperature and atmospheric pressure (Zakaria, Osman, \& Abdullah, 2013). Estimations of the amount of BOG that evaporates are readily available in many heat transfer textbooks such as (Kreith, Manglik, \& Bohn, 2001) and several studies (Adom et al., 2010; Chen et al., 2004; Ming-shun et al., 2009) and are conducted by applying energy balance and assuming steady flow of heat leakage through the LNG tank shell so that the daily amount of BOG can be estimated in terms of BOR as

$$
B O R=\frac{q}{\rho V h_{f g}} \times 24 \times 3600 \times 100 \%
$$

where $\mathrm{q}$ is the total heat leaking through the insulation to the $\operatorname{cargo}(\mathrm{J} / \mathrm{sec})$, which can be read directly using ANSYS Fluent, $\mathrm{h}_{\mathrm{fg}}$ is the latent heat of vaporization $(511000$ $\mathrm{J} / \mathrm{kg}$ ) (Guyer, 1999) and $\rho$ and $\mathrm{V}$ are the density and volume of the LNG inside the tank, taken as $424 \mathrm{~kg} / \mathrm{m}^{3}$ (Guyer, 1999) and $40447 \mathrm{~m}^{3}$ respectively. Since one is not interested in details regarding the thermoeconomic change, Equation 2 is sufficient for preliminary evaluation of the system (Dimopoulos \& Frangopoulos, 2008).

\section{VALIDATION}

The model is validated by comparing the results from a simulation by Hasan, et al. (2009). The software used by Hasan, et al. (2009) was Aspen HYSYS 2004.2 to simulate various conditions for a complete trip of LNG composed of $81.5 \%$ methane (Hasan et al., 2009). Investigate the effect of average ambient temperature to the Cargo Boil Off Gas (CBOG) with different overall heat. For validation purposes, the same LNG tank size, heat thermal transmittance and ambient condition were considered. However, there are discrepancies in LNG tank type and LNG grade composition. The composition used in the present validation is based on the Snohvit Project in 2007, located in Norway. Latent Heat Vaporization (LHV) and density are 640360J/kg and $450 \mathrm{~kg} / \mathrm{m}^{3}$ respectively (Zakaria, Osman, \& Musa, 2012), compared with pure methane which has lower LHV and a density which was $511000 \mathrm{~J} / \mathrm{kg}$ and $424 \mathrm{~kg} / \mathrm{m}^{3}$ respectively.

The changes seen were linear and the same behavior is expected to be obtained in the analysis in this paper. Further investigation by Hasan, et al. (2009) has also shown that the BOG produced during a laden voyage increases linearly even dynamic simulation have been done. The resulting data was extracted and plotted in Figure 2 for different ambient temperatures and $\mathrm{U}$. The linear behavior allows us to estimate the 
BOR by measuring the slope for a particular line. The BOR calculated by Hasan, et al. (2009) is $0.10 \%$ cargo per day while BOR for present study is $0.11 \%$ cargo per day for the same $\mathrm{U}$ and ambient temperature

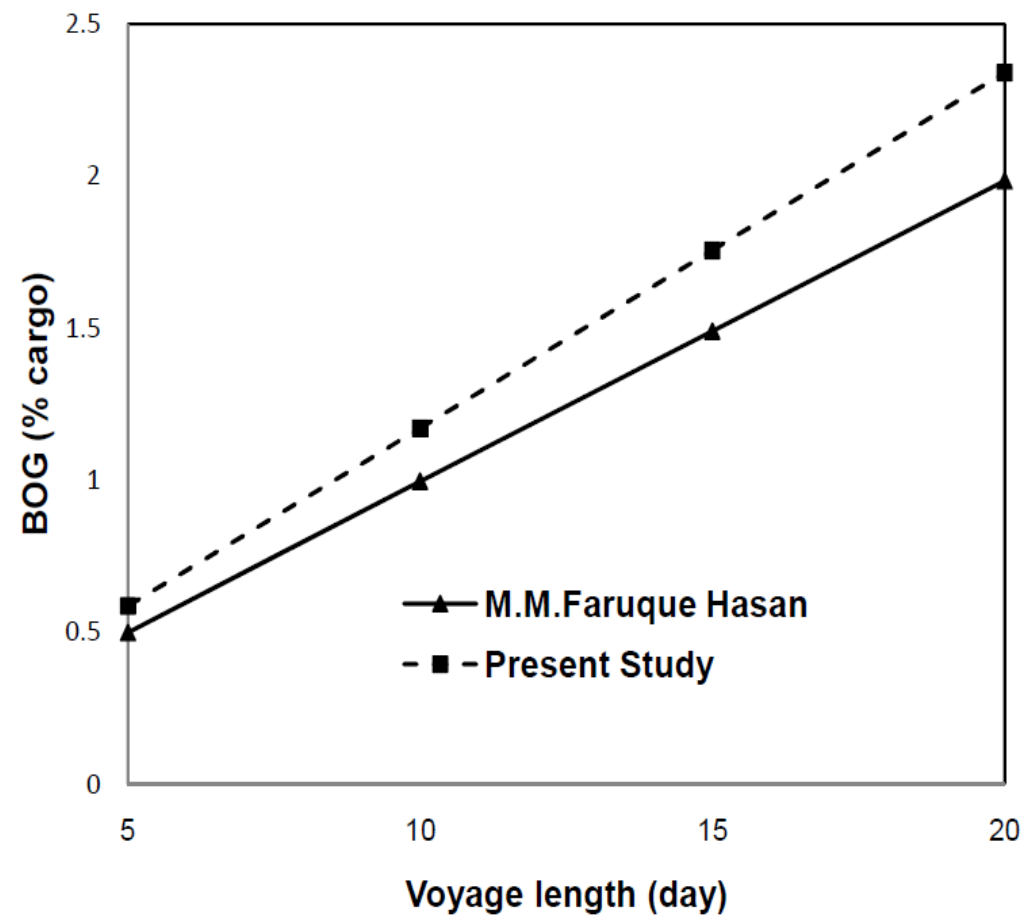

Figure 2. Comparison study of the temperature effect on the BOG with voyage length of 20 days.

\section{RESULTS AND DISSCUSSION}

Both transient dynamic and steady state models were implemented for analysis in this paper. ANSYS Fluent software was used as a simulation basis for all cases. All simulation cases are based on two sets of parameters. One set are independent parameters, fixed and the same for all runs, while the other are case dependent parameters and varies for each simulation. For independent parameters, all cases used the same LNG tanker size $\left(40447 \mathrm{~m}^{3}\right.$ ), same LNG tanker type (GTT NO96 membrane), same cofferdam ambient condition $\left(5^{\circ} \mathrm{C}\right)$, same operation mode (fully laden), same operating pressure $(1$ bar) and same LNG grade (100\% methane). The ambient temperature and overall heat transmittance was considered the dependent parameter. Although to the use of a transient dynamic simulation model for laden voyages is recommended due to changes in composition and temperature of LNG, as reported by Hasan, et al. (2009), the change in temperature of LNG is not really significant because at temperatures slightly higher than the boiling temperature of LNG, BOG begins to generate and release depending on the BOG management method. LNG will thus remain at most on the boiling temperature in order to maintain its liquid phase.

Transient analysis furthermore shows that heat leakage through insulation will archive a steady state after approximately five days, even for the best cases (overall heat transmittance $0.1 \mathrm{~kJ} / \mathrm{h} \cdot \mathrm{m}^{2} . \mathrm{K}$ ) and up to two days of the voyage for the worst cases (overall heat transmittance $0.4 \mathrm{~kJ} / \mathrm{h} \cdot \mathrm{m}^{2} . \mathrm{K}$ ). Higher thermal conductance of insulation is 
expected to give more time for BOR to achieve a steady state reading. Since there is no way in the real practice that a voyage could end after only five days, the various cases should be investigated in the steady state model in order to reduce computational works and simulation time. To gain insight into the economic view of the problem cases, assuming that LNG prices are $\$ 386.5$ USD per ton, for $\mathrm{U}=0.5 \mathrm{~kJ} / \mathrm{h} \cdot \mathrm{m}^{2} . \mathrm{K}, 0.206 \% \mathrm{~kg} / \mathrm{kg}$ LNG evaporates per day, which is equivalent to $35328 \mathrm{~kg}$ or 13654 USD losses per day. If the typical voyage duration for a complete trip is around 20 days, the loss is $\$ 273,085$ USD per voyage.

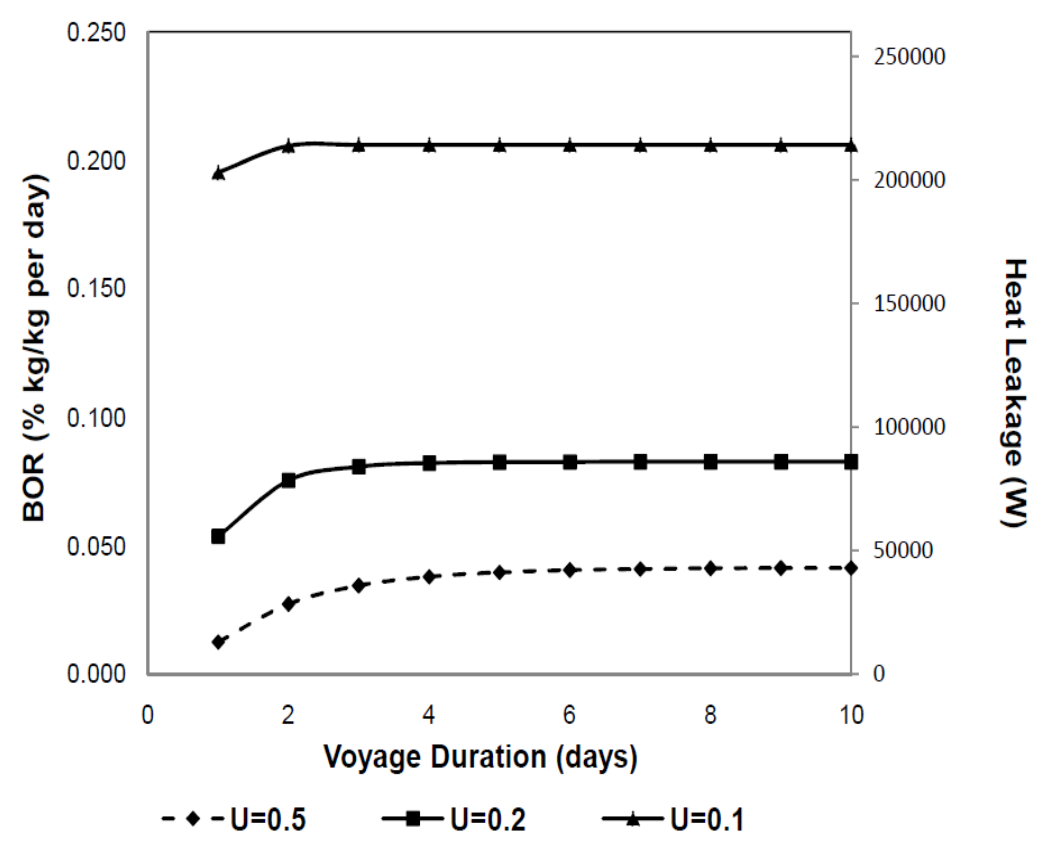

Figure 3. Effect of voyage duration on heat leakage and BOR.

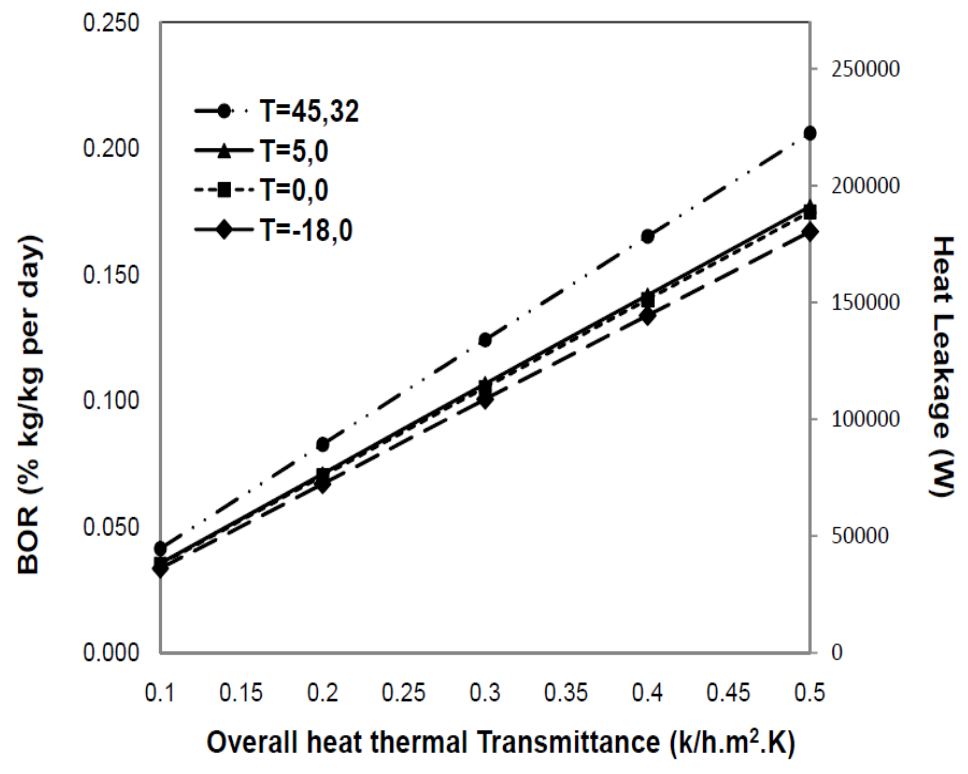

Figure 4. Effect of BOR and heat leakage overall thermal conductivity, U. 
Figure 4 shows that the BOR is linearly increased with the increment of overall heat transmittance used. This relationship enables us to introduce the linear coefficient for each case. For air temperature $45^{\circ} \mathrm{C}$ and seawater temperature $32^{\circ} \mathrm{C}$, every increase of $0.1 \mathrm{~kJ} / \mathrm{h} \cdot \mathrm{m}^{2} . \mathrm{K}$ heat thermal transmittance will increase LNG BOR by about $0.0416 \%$ $\mathrm{kg} / \mathrm{kg}$ per day. As expected, lower ambient temperature will produce a small linear coefficient as well. An LNG tank with air temperature $5^{\circ} \mathrm{C}$ and seawater temperature $0^{\circ} \mathrm{C}$ will increase BOR about $0.03536 \% \mathrm{~kg} / \mathrm{kg}$ per day for every $0.1 \mathrm{~kJ} / \mathrm{h} . \mathrm{m}^{2} . \mathrm{K}$ increase of overall heat transmittance. Increases of BOR of about $0.03492 \% \mathrm{~kg} / \mathrm{kg}$ per day for every $0.1 \mathrm{~kJ} / \mathrm{h} \cdot \mathrm{m}^{2} . \mathrm{K}$ overall heat transmittance increment have been found for LNG tanks with $0^{\circ} \mathrm{C}$ for both ambient air and seawater temperatures. The lowest ambient condition studied in this paper, which was $-18^{\circ} \mathrm{C}$ ambient air temperature and $0^{\circ} \mathrm{C}$ seawater, will increase BOR approximately $0.03334 \% \mathrm{~kg} / \mathrm{kg}$ per day if for every 0.1 $\mathrm{kJ} / \mathrm{h} \cdot \mathrm{m}^{2} . \mathrm{K}$ overall heat transmittance is increased.

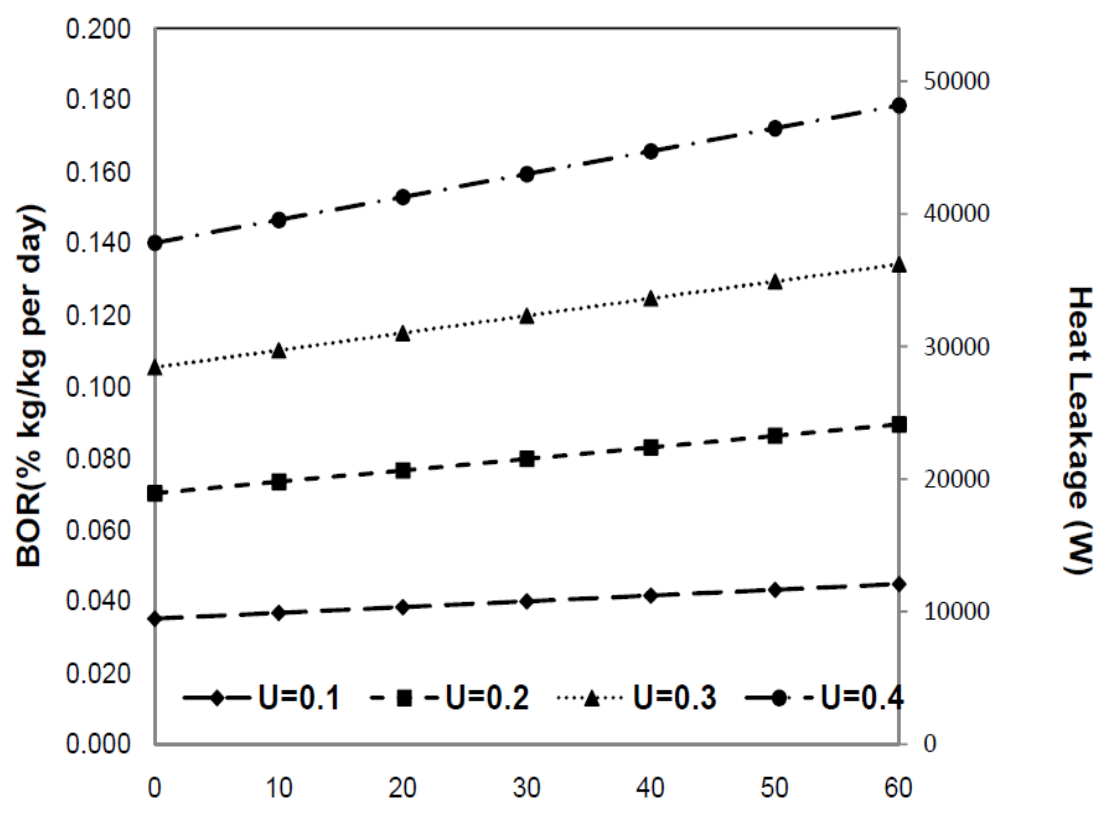

Average ambient Tempreature $\left({ }^{\circ} \mathrm{C}\right)$

Figure 5. The effect of BOR and heat leakage as a function of average ambient temperature with typical different overall thermal conductivity.

In order to investigate the effect of ambient temperature for general environmental conditions, the average and same temperature for air and seawater were taken into consideration in analysis while maintaining cofferdam temperature at $5^{\circ} \mathrm{C}$ as shown in Figure 7. This shows that for heat thermal transmittance $0.1 \mathrm{~kJ} / \mathrm{h} . \mathrm{m}^{2} . \mathrm{K}$, $0.2 \mathrm{~kJ} / \mathrm{h} \cdot \mathrm{m}^{2} . \mathrm{K}, 0.3 \mathrm{~kJ} / \mathrm{h} \cdot \mathrm{m}^{2} . \mathrm{K}$ and $0.4 \mathrm{~kJ} / \mathrm{h} \cdot \mathrm{m}^{2} \cdot \mathrm{K}$, the BOR increases by $0.0002 \% \mathrm{~kg} / \mathrm{kg}$ per day, $0.0003 \% \mathrm{~kg} / \mathrm{kg}$ per day, $0.0005 \% \mathrm{~kg} / \mathrm{kg}$ per day and $0.0006 \% \mathrm{~kg} / \mathrm{kg}$ per day respectively, for every $1{ }^{\circ} \mathrm{C}$ increase of average ambient temperature. In addition, the results presented also enable us to estimate the heat leakage for corresponding BOR, ambient condition and heat thermal transmittance. The same interpretation is expected due to the linear relationship between BOR and heat leakage. 


\section{CONCLUSIONS}

This paper has successfully investigated the factors affecting BOR under realistic parameter and boundary conditions for specific LNG tankers. The linear behavior for each parameter effect enables us to illustrate the relationship in a single coefficient. However the coefficient only can be used after five days of voyage where the heat transfer has entered steady state mode. Results obtained are also in line with the IMO requirement or standard of BOR provided for a typical LNG carrier which ranges from 0.1 to $0.15 \% / \mathrm{kg} / \mathrm{kg}$ per day. Further investigation should be done to determine the heat thermal transmittance value for each insulation material used, such as perlite, aerogel, or polyurethane foam.

\section{ACKNOWLEDGEMENTS}

This work was sponsored by Universiti Teknikal Malaysia Melaka (UTeM) under a Short Term Grant (STG) with grant no. PJP/2012/FKM(12A)/S01087. The author also greatly appreciates support from Kementerian Pengajian Tinggi (KPT) and Universiti Teknologi Malaysia (Duwig, Stankovic, Fuchs, Li, \& Gutmark) for sponsorship of the studies.

\section{REFERENCES}

Adom, E., Islam, S. Z., \& Ji, X. (2010). Modeling of boil off gas in lng tanks: A case study. International Journal of Engineering and Technology, 2(4), 292-296.

Chen, Q.-S., Wegrzyn, J., \& Prasad, V. (2004). Analysis of temperature and pressure changes in liquefied natural gas (lng) cryogenic tanks. Cryogenics, 44(10), 701709.

Dimopoulos, G. G., \& Frangopoulos, C. A. (2008). A dynamic model for liquefied natural gas evaporation during marine transportation. International Journal of Thermodynamics, 11(3), 123-131.

Duwig, C., Stankovic, D., Fuchs, L., Li, G., \& Gutmark, E. (2007). Experimental and numerical study of flameless combustion in a model gas turbine combustor. Combustion Science and Technology, 180(2), 279-295.

Gharehghani, A., Hosseini, R., \& Yusaf, T. (2013). Investigation of the effect of additives to natural gas on heavy-duty si engine combustion characteristics. Journal of Mechanical Engineering and Sciences, 5, 677-687.

Guyer, E. C. (1999). Handbook of applied thermal design: CRC press.

Hasan, M. F., Zheng, A. M., \& Karimi, I. (2009). Minimizing boil-off losses in liquefied natural gas transportation. Industrial \& engineering chemistry research, 48(21), 9571-9580.

Kreith, F., Manglik, R. M., \& Bohn, M. S. (2001). Principles of heat transfer: Cengage Learning.

Ming-shun, Z., Bo-yang, L., \& Yun-qiu, Z. (2009). Finite element analysis on temperature field of insulated cabin for lng carrier based on ansys. Paper presented at the Intelligent Computation Technology and Automation, 2009. ICICTA'09. Second International Conference on.

Querol, E., Gonzalez-Regueral, B., García-Torrent, J., \& García-Martínez, M. (2010). Boil off gas (bog) management in spanish liquid natural gas (lng) terminals. Applied Energy, 87(11), 3384-3392. 
Romero, J., \& Mosquera, I. (2005, 26-30 September). Maritime transportation and exploitation of ocean and coastal resources. Paper presented at the Proceedings of the 11th International Congress of the International Maritime Association of the Mediterranean, Lisbon.

Shin, M. W., Shin, D., Choi, S. H., \& Yoon, E. S. (2008). Optimal operation of the boiloff gas compression process using a boil-off rate model for lng storage tanks. Korean Journal of Chemical Engineering, 25(1), 7-12.

Yusaf, T., Baker, P., Hamawand, I., \& Noor, M. M. (2013). Effect of compressed natural gas mixing on the engine performance and emissions. International Journal of Automotive and Mechanical Engineering, 8, 1416-1429.

Zakaria, M. S., Osman, K., \& Abdullah, H. (2013). Greenhouse gas reduction by utilization of cold lng boil-off gas. Procedia Engineering, 53, 645-649.

Zakaria, M. S., Osman, K., \& Musa, M. (2012). Boil-off gas formation inside large scale liquefied natural gas (lng) tank based on specific parameters. Applied Mechanics and Materials, 229, 690-694.

Zellouf, Y., \& Portannier, B. (2011). First step in optimizing lng storages for offshore terminals. Journal of Natural Gas Science and Engineering, 3(5), 582-590. 